\title{
The 9th International Workshop on Modeling the Ocean (IWMO 2017) in Seoul, Korea, July 3-6, 2017
}

\author{
Lie-Yauw Oey ${ }^{1} \cdot$ Yign Noh $^{2} \cdot$ Jarle Berntsen $^{3} \cdot$ Sung Yong Kim ${ }^{4} \cdot$ Humio Mitsudera $^{5} \cdot$ Tal Ezer $^{6}$ \\ Published online: 25 November 2019 \\ (C) Springer-Verlag GmbH Germany, part of Springer Nature 2019
}

The 9th International Workshop on Modeling the Ocean (IWMO 2017) was held in the modern campus of Yonsei University, Seoul, Korea, from July 3-6 2017. The workshop was attended by about 80 participants from countries all around the world, many of whom were young and earliercareer scientists: students and postdocs. Papers were presented covering a broad range of topics on field observations, analyses, and modeling: wave and air-sea interaction dynamics, climate variability, basin-scale processes and coastal oceanography, sea-ice dynamics, sediment transport, tropical cyclones, biogeochemical-physical coupling, boundary currents, sea-level rise, extreme events, ocean prediction and others. We were pleased to witness very high-quality research and presentations, many from young students and scientists. Thirty three (33) young scholars participated in the Outstanding Young Scientist Award (OYSA) competition; congratulations to all of them! The finalists of the IWMO-2017 OYSA were:

R. Olson (Yonsei University, Korea), Y. Ushijima (Kyoto University, Japan), Y. Choi (Yonsei University, Korea), and Y. J. Tak (Seoul National University, Korea).

Responsible Editor: Jörg-Olaf Wolff

Lie-Yauw Oey

lyo@alumni.princeton.edu

1 Institute of Hydrological and Oceanic Sciences, National Central University, Taoyuan, Taiwan

2 Department of Atmospheric Sciences, Yonsei University, 134 Shinchon-dong, Seodaemun-gu, Seoul 120-749, Korea

3 Department of Mathematics, University of Bergen, Bergen, Norway

4 Department of Mechanical Engineering, Korea Advanced Institute of Science and Technology (KAIST), Daejeon, Korea

5 Institute of Low Temperature Science, Hokkaido University, Sapporo, Japan

6 Center for Coastal Physical Oceanography, Old Dominion University, Norfolk, VA, USA
The 8 papers in this Topical Collection were selected from a total of about 30 submitted papers after they underwent the usual process of reviews and revisions. There were at least 2 reviewers for each paper. The reviews were solicited from both the workshop attendees and the scientific community at large. Below are short summaries of the papers in the topical collection (alphabetically ordered).

Berntsen et al. (2018) conducted high-resolution model experiments of dense water cascading down a continental slope, focusing on bottom boundary layer dynamics. The authors used a terrain-following model and found that with quadratic drag law and bottom drag coefficient calculated to fit the logarithmic law of the wall, the model could efficiently simulate bottom Ekman layer dynamics in good agreements with very fine-grid modeling using the no-slip bottom boundary condition.

Hong et al. (2018) applied a current and wave coupled model to conduct model sensitivity, with and without coupling, in predicting waves and surges induced by Typhoon Bolaven (2012) that made landfall upon the Korean Peninsula. With coupling, ocean currents reduced significantly the wave height on the right-hand side of the advancing storm, improving the peak height and timing compared with the uncoupled simulation. Surge peak was improved using a wind stress formula that incorporated the storm-induced wave height.

Kim et al. (2018) conducted idealized experiments to study the role of cold-water formation and planetary vorticity gradient ( $\beta$ effects) in the generation of the East Korea warm current - a western boundary current - in the East/Japan Sea. Cold water was shown to control the strength of the East Korea warm current, followed by the $\beta$ effects, consistent with observations.

Rusdiansyah et al. (2018) applied a finite-volume unstructured grid numerical model at high resolution (horizontal grid $\sim 25 \mathrm{~m}$ ) to assess the potential impacts of the construction of a "giant sea wall" on the three-dimensional circulation of Jakarta Bay, Indonesia. They demonstrated the feasibility of 
such a high-resolution unstructured grid model in accommodating very complex bathymetry and coastline, and in providing quantitative assessments of the modified circulation useful for local planning and management.

Stashchuk et al. (2018) tracked passive particles using currents from a general circulation model to simulate larval dispersal over the Anton Dohrn Seamount in the North Atlantic Ocean. The simulation shows that the majority of particles remains in the same depth band where they were initially released, suggesting that physical circulation processes, e.g., baroclinic tidal currents, may provide a potential isolating mechanism for the larvae; only $\sim 10 \%$ of particles can undergo maximum dispersal with successful recruitment to the benthos.

Wang and Xu (2018) used the Met Office Hadley Center ocean reanalysis data to study the decadal trends of isothermal layer, mixed layer, and barrier layer depths in the tropical Pacific, from 1979 to 2015 . The authors found that all 3 layers have an increasing trends in the western tropical Pacific, due to the dominance of negative Pacific Decadal Oscillation during the analysis period which explains approximately $25 \%$ of the trends. El Nino Southern Oscillation explains only $1.7 \%$ while the remaining increasing trends are due to global warming and/or other long-period processes.

Yin et al. (2018) used an ensemble Kalman filter data assimilation scheme to assimilate currents measured by an array of high-frequency radar system into a three-dimensional circulation model of the Gulf of Thailand. The goal is to test the optimal placement of the observational array that can yield model results in good agreements with observations. The optimal network of radars obtained in the study could provide a useful guidance for future design of observing system in the region.

Zhang et al. (2018) used Argo and satellite remote sensing observations to analyze the three-dimensional structures of mesoscale eddies on eastern and western sides of the Luzon Strait connecting the North Pacific Ocean to the South China Sea. The method tracks individual eddies on both sides, from 2002 to 2014, and then composited the salinity and temperature fields within the eddies. The authors found that mesoscale eddies are much deeper on the eastern side than on the western side, 200 400 m compared with $\sim 100 \mathrm{~m}$. Dipole structure near the surface gradually turns into a monopole in the deep layer.

Acknowledgements The host of the meeting, Prof. Yign Noh, and the local scientists and staff of Yonsei University are thanked for their warm hospitality and help during the workshop. LYO wishes to thank Prof. Noh in particular for his tremendous effort and hard work in preparations for the workshop. We also thank the Chief Editor Prof. Jörg-Olaf Wolff of Ocean Dynamics for the help and encouragements throughout the process of preparing this Topical Collection. Last but not least, we thank all the reviewers for their help in ensuring that the submitted manuscripts are held to the highest standard.

\section{References}

Berntsen J, Alendal G, Avlesen H, Thiem O (2018) Effects of the bottom boundary condition in numerical investigations of dense water cascading on a slope. Ocean Dyn 68(4-5):553-573. https://doi.org/10. 1007/s10236-018-1138-8

Hong JS, Moon JH, Kim T, Lee JH (2018) Impact of ocean-wave coupling on typhoon-induced waves and surge levels around the Korean Peninsula: a case study of Typhoon Bolaven. Ocean Dyn 68(11): 1543-1557. https://doi.org/10.1007/s10236-018-1218-9

Kim YY, Cho YK, Kim YH (2018) Role of cold water and beta-effect in the formation of the East Korean Warm Current in the East/Japan Sea: a numerical experiment. Ocean Dyn 68(8):1013-1023. https:// doi.org/10.1007/s10236-018-1175-3

Rusdiansyah A, Tang Y, He Z, Li L, Ying Y, Surya MY (2018) The impacts of the large-scale hydraulic structures on tidal dynamics in open-type bay: numerical study in Jakarta Bay. Ocean Dyn 68(90): 1141-1154. https://doi.org/10.1007/s10236-018-1183-3

Stashchuk N, Vlasenko V, Howell KL (2018) Modelling tidally induced larval dispersal over Anton Dohrn Seamount. Ocean Dyn 68(11): 1515-1526. https://doi.org/10.1007/s10236-018-1206-0

Wang L, Xu F (2018) Decadal variability and trends of oceanic barrier layers in tropical Pacific. Ocean Dyn 68(9):1155-1168. https://doi. org/10.1007/s10236-018-1191-3

Yin X, Shi J, Qiao F (2018) Evaluation on surface current observing network of high frequency ground wave radars in the Gulf of Thailand. Ocean Dyn 68(4-5):575-587. https://doi.org/10.1007/ s10236-018-1149-5

Zhang WZ, Ni Q, Xue H (2018) Composite eddy structures on both sides of the Luzon Strait and influence factors. Ocean Dyn 68(11):15271541. https://doi.org/10.1007/s10236-018-1207-z 